\title{
BACIAS HIDROGRÁFICAS INTERMITENTES SAZONAIS E POTENCIALIDADES HIDROAMBIENTAIS NO NORDESTE SETENTRIONAL BRASILEIRO
}

\author{
FLÁVIO RODRIGUES DO NASCIMENTO ${ }^{1}$ \\ Universidade Federal Fluminense
}

\section{Introdução}

Em sua mais ampla acepção, a vida depende da água. A água é um recurso essencial como solvente universal, componente bioquímico dos seres vivos - em sua higidez biológica e funcional; meio de sobrevivência para biodiversidade e dinamização de variações genéticas; elemento de valores sociais, culturais e estéticos; insumo na produção de bens e serviços de consumo intermediários e finais, dentre outros atributos.

Trata-se da substância mais abundante na superfície terrestre, participando dos processos modeladores geomórficos pela dissolução de materiais terrígenos e do transporte de partículas. Como melhor e mais comum solvente disponível na natureza, sua função no intemperismo químico é evidenciada pela hidrólise. Em ambientes limnológicos, a água transporta partículas, desde a forma iônica (em solução) a cascalhos e blocos, constituindo-se como meio mais eficiente de erosão da superfície terrestre. Fundamentalmente a água mantém a vida sobre o Planeta pela fotossíntese, produzindo biomassa na reação entre gás carbono $\left(\mathrm{CO}_{2}\right)$ e água $\left(\mathrm{H}_{2} \mathrm{O}\right)$.

Atualmente, em vista da relação usos múltiplos versus escassez, a água doce é questão de geopolítica internacional, onde se destacam propostas para estudos integrados de bacias hidrográficas com

\footnotetext{
${ }^{1}$ Professor do Programa de Pós-Graduação e do Departamento de Geografia da Universidade Federal Fluminense/RJ. Líder do Grupo de Pesquisa Núcleo de Estudos e Planejamento em Hidrogeografia (NEPH). Contato: frngeo2001@yahoo.com.br.
} 
gerenciamento de recursos hídricos para fins do crescimento econômico e busca do desenvolvimento.

Nesse contexto, como curso natural de água doce, com canais definidos e fluxo constante ou sazonal para o Oceano Atlântico, as Bacias intermitentes sazonais do Nordeste Seco do Brasil (a exemplo de PiranhasAçu, na Paraíba e Rio Grande do Norte; do rio Mossoró, no Rio Grande do Norte; rio Curu, no Ceará; rio Paraíba, no estado homônimo, dentre outras) definem áreas de captação da água de precipitação, demarcadas por divisores topográficos, nos quais toda a água captada converge para um ponto em comum de saída, o exutório, constituindo bacias hidrográficas com padrões de drenagem em função do escoamento do tipo exorreico. Os recursos hídricos, ademais, no âmbito de cada bacia hidrográfica, potencializam a diversidade biológica e as variações facilógicas de manchas de solo, pelo arranjo espaço-temporal das águas, elemento essencial à vida.

Assim, concebendo as bacias intermitentes sazonais do Nordeste do Brasil na condição de unidade territorial de planejamento, torna-se urgente reler os paradigmas de desenvolvimento regionais que, atrelados ao nacional e ao internacional, ante a globalização, determinam padrões degradadores e comprometedores de manejo das atividades produtivas, com destaque para as campesinas. Ademais, as culturas locais são mais facilmente adaptadas à realidade nacional do que às tecnologias "de ponta" na ambientação de novas culturas, isto pressupondo estratégias ecologicamente harmônicas.

\section{Bacias intermitentes sazonais no Nordeste brasileiro}

O Brasil tem uma das mais extensas e densas redes hidrográficas do mundo, com descarga média total da ordem de $5.619 \mathrm{~km} 3 / \mathrm{ano}$, ou seja, aproximadamente $14 \%$ dos $41 \mathrm{mil} \mathrm{km} 3 /$ ano de deflúvio dos rios no mundo. Esse montante chega a ser reduzido, proporcionalmente, na região Nordestina seca (Cunha, 2001), com rios efêmeros e temporários que nascem no domínio cristalino-aflorante no semiárido, em uma superfície aproximada de $400.000 \mathrm{~km}^{2}$ (REBOUÇAS, 2002; NASCIMENTO, 2013).

Sobre essa região, das 24 unidades hidrográficas de planejamento (bacias integradas), consideradas por Filho et al. (1994), em uma área total de $1.429 .900 \mathrm{~km}^{2}, 19$ são compostas por rios intermitentes sazonais com uma superfície de $837.700 \mathrm{~km}^{2}$ ou, $58,58 \%$ do total. Dentre as bacias 
intermitentes pode ser assinalada a do Acaraú conjugada com a bacia do Coreaú, em uma superfície de $30.500 \mathrm{~km}^{2}$.

No caso das bacias intermitentes, a disponibilidade hídrica, "permanente" ou duradoura, é função da regularização interanual dos deflúvios naturais por volumes constantes provenientes de reservatórios (VIEIRA, 2002), como se verifica no Acaraú com os açudes Edson Queiroz (250,5 milhões de $\mathrm{m}^{3}$ ) e Araras Norte (860.9 milhões de $\mathrm{m}^{3}$ ), por exemplo. Com base em Filho et al. (1994), respaldado por Vieira (IBID) e Rebouças (1997; 2002a), foram comparadas as principais características de potencialidades e disponibilidades das regiões hidrográficas da SUDENE, no geral, e em particular, as bacias dos rios Acaraú e Coreaú

No que condiz à disponibilidade hídrica de rios, a maioria dos estados nordestinos situa-se na classe regular (1000-2000 m/hab/ano). Com atenção ao Ceará, a relação é de $2.279 \mathrm{~m}^{3} / \mathrm{hab} / \mathrm{ano}$, com potencial hídrico de $15,5 \mathrm{~km}^{3}$. O Nordeste apresenta 1.657,601 m³/hab/ano, ou 4,6\% da disponibilidade hídrica social, tomando-se por base um potencial hídrico de 186,2 km³/ano (REBOUÇAS, 2002a).

Nesse contexto, o estado do Ceará é um dos principais laboratórios brasileiros das inovações políticas sobre a gestão de bacias hidrográficas para gerência da oferta de água sob controle estatal. Em especial, é necessário estudar os recursos hídricos na condição de fator básico de melhoria da qualidade ambiental.

A bacia hidrográfica - ao passo que é a unidade de gerenciamento integrado dos recursos naturais, sobretudo dos mananciais com fins de seu aproveitamento -, coloca os recursos hídricos na condição de elemento indispensável à vida e como insumo às atividades produtivas, pois o uso pelas populações para irrigação, indústrias, atividades de lazer, dentre os outros múltiplos empregos, requer fontes em qualidade e quantidade saudáveis e seguras ao mercado. Com essa necessidade, o Estado do Ceará, que tem como agravante ao aproveitamento dos recursos naturais a semiaridez, foi um dos primeiros da Federação - além de São Paulo e Paraná - a elaborar plano de recursos hídricos; isso em 1992. Por este motivo, o Estado do Ceará/Nordeste do Brasil, e especificamente, sua porção centro-norte a partir da Bacia Hidrográfica do rio Acaraú, serão destacados na condição de exemplos analíticos deste trabalho.

O quadro hidrográfico desse estado individualiza bacias hidrográficas e conjuntos de bacias que perfazem o montante de 11 grandes bacias hidrográficas. Dessas, a bacia do rio Jaguaribe $\left(74.621 \mathrm{~km}^{2}\right)$ foi 
compartimentada em 5 bacias, e a bacia Metropolitana $\left(15.085 \mathrm{~km}^{2}\right)$ é formada a partir do agrupamento de 16 bacias independentes. Essas unidades de planejamento, associadas ou não, são: Alto Jaguaribe (24.538 $\mathrm{km}^{2}$ ), rio Salgado $\left(12.216 \mathrm{~km}^{2}\right)$, Médio Jaguaribe $\left(10.509 \mathrm{~km}^{2}\right)$, rio Banabuiú $\left(19.810 \mathrm{~km}^{2}\right)$ e Baixo Jaguaribe $\left(4.970 \mathrm{~km}^{2}\right)$, que são subdivisões da bacia do Jaguaribe; Parnaíba $\left(16.901 \mathrm{~km}^{2}\right)$, Curu $\left(9.000 \mathrm{~km}^{2}\right)$, Coreaú $\left(10.500 \mathrm{~km}^{2}\right)$ e Acaraú $\left(14.560 \mathrm{~km}^{2}\right)$, que teve sua área atualizada e principais características abordadas neste trabalho (Figura 01).

\section{Contexto geoambiental da Bacia do rio Acaraú - Ceará}

A Bacia Hidrográfica do rio Acaraú, que marca o limite ocidental do semiárido brasileiro no contexto das bacias intermitentes sazonais do Nordeste Seco, pertence ao grupo de bacias do Atlântico Nordeste Oriental. Apresenta regime fluvial de enchentes durante as chuvas de verão-outono, sendo a terceira em vazão, com 4,45 1/s/hm² (MMA/SRH, 2004); com vulnerabilidade natural às secas e criticidade de escassez hídrica, o que pode potencializar os conflitos pela água (FILHO et al., 1994), inferior a $1 / 5$ da vazão específica média nacional, que é de 211/s/km² (ABRH, 1987 in VIEIRA, 2002). Segundo o Plano Nacional de Recursos Hídricos, a bacia do Acaraú é parte integrante da Área Especial de Planejamento no contexto da desertificação. 

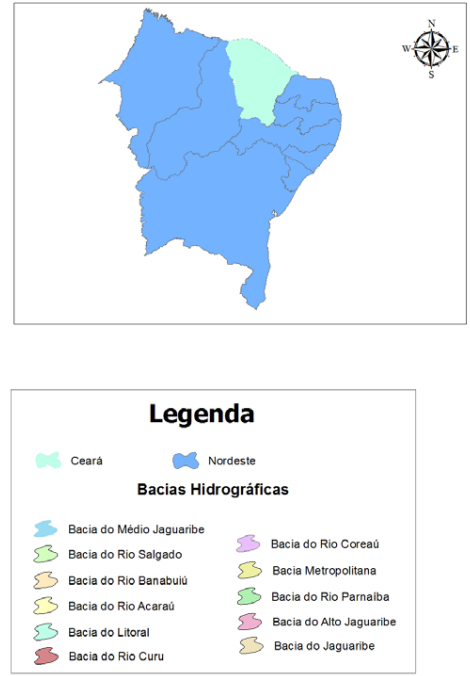

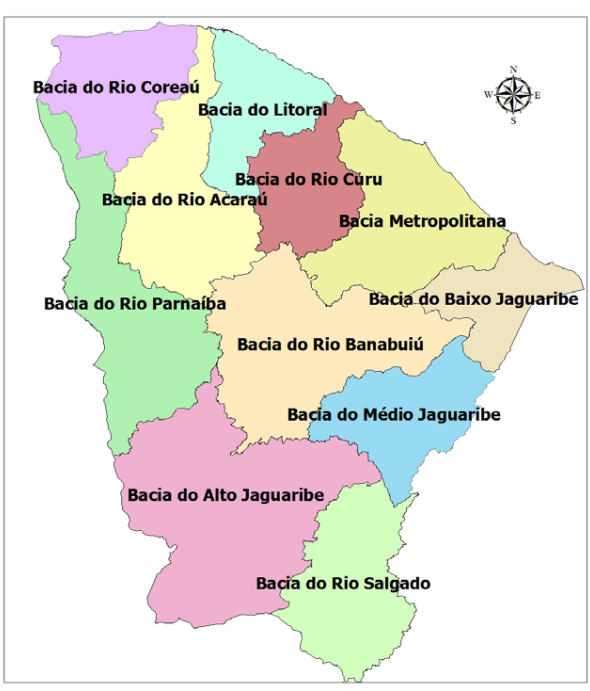

Adaptado de FUNCEME

Figura 1 - Bacias hidrográficas como unidades de planejamento. Destaque para a Bacia do rio Acaraú - estado do Ceará.

A bacia hidrográfica do rio Acaraú é a mais importante das regiões norte e oeste do Estado porque drena a principal cidade desses setores, Sobral. O rio Acaraú nasce na vertente ocidental da Serra das Matas, no Município de Monsenhor Tabosa, na cota de $600 \mathrm{~m}$ e tem, longitudinalmente, extensão máxima de $307,5 \mathrm{~km}$, considerando $17,5 \mathrm{~km}$ do açude Araras Norte. Seu curso tem orientação predominante sul-norte, em disposição alongada, e a bacia tem forma de pêra.

Trabalhos de sensoriamento remoto, à revelia da classificação do Governo Estadual de apenas 25 municípios, dão conta de que a bacia de drenagem entrecorta 31 municípios de maneira integral, parcial ou somente uma pequena parcela de seus territórios. Os grifados a seguir foram os que tomamos como base para este trabalho: no baixo curso tem-se Acaraú, Cruz, Bela Cruz, Marco, Morrinhos; no médio curso, Santana do Acaraú, Meruoca, Alcântaras, Massapê, Sobral e Forquillha. Finalmente, em seu alto curso: Groaíras, Cariré, Pacujá, Graça, Reriutaba, Varjota, Mucambo, Santa Quitéria, Catunda, Hidrolândia, Pires Ferreira, Nova Russas, Ararendá, Canindé, São Benedito, Ibiapina, Ipueiras, Ipu, Mosenhor Tabosa e Tamboril. 
Seus principais tributários destacam-se pelo porte. $\mathrm{Na}$ margem esquerda, o rio Jaibaras - que tem suas nascentes no front central da Ibiapaba na divisão com a bacia do Parnaíba, configurando curso d'água consequente, e os pequenos cursos d'água que tomam orientação oposta e de natureza obsequente - são o destaque. Nos maciços residuais, encontram-se as nascentes dos outros rios mais importantes. Além do já mencionado exutório na Serra das Matas, divisor de águas com a bacia do Banabuiú, o rio Macacos tem suas cabeceiras. O principal afluente do Acaraú, o rio Groaíras $\left(2.917,3 \mathrm{~km}^{2}\right)$, apresenta nascentes na Serra do Machado, divisor de águas com a bacia do Curu. Completando os tributários da margem direita, encontram-se os rios Jacurutu e Madeiras, respectivamente com nascentes no Serrote das Cobras e em pequenos maciços no município de Forquilha, na divisa com a bacia do Litoral. Com exceção do uso de pequenos botes e canoas nos trechos perenizados, açudes e na cidade de Sobral, o único trecho navegável é o do estuário, principalmente do porto de Acaraú até a foz.

A Bacia do Acaraú entrecorta diferentes unidades geomorfológicas, como planalto sedimentar e maciços residuais, depressões periféricas e tabuleiros pré-litorâneos, entalhando planícies fluviais, fluviolacustres e a planície litorânea, em busca do nível de base de sul a norte, com extensão longitudinal de $225 \mathrm{~km}$. Os terrenos cristalinos são relevantes por sua primazia espacial. Os rios nesse trecho têm padrão dendrítico e retangular (sob forte controle estrutural, sobretudo nas serras). Tomando-se por base seu médio-baixo curso, os terrenos sedimentares pronunciam-se com os sedimentos da Formação Barreiras e holocênicos da planície litorânea. Neste trecho a drenagem predominante é de padrão paralelo e de baixa densidade, chegando a formar meandros nas faixas aluviais. Na planície fluviomarinha os rios apresentam padrões de canais anastomosados, a par de baixos gradientes de declividades.

Nesse caminho das águas os recursos hídricos apresentam-se ora em superfície ora em subsuperfície, todavia, as condições climatéricas, sobretudo as chuvas, são os principais elementos de renovação das águas, diretamente subordinadas pelas morfoestruturas bem como por outros elementos biofísicos, sendo que os açudes públicos contribuem para minimizar o déficit hídrico com reservas de águas para usos múltiplos.

Nos sertões do Acaraú, com rochas cristalinas, há grande frequência e densidade de rios e riachos intermitentes com escoamento espasmódico. A disponibilidade hídrica, além das chuvas, está em virtude de açudes, 
barragens captadoras de veios fluviais - perenizados ou não - e de lagoas mantenedoras das águas residuais de forma natural.

Nas depressões circunjacentes o entalhe da drenagem é pouco incisivo, com vales modestamente escavados, em relevo aplainado e pouco dissecado. Outras características condizem com: maior deposição linear de matérias para formação de solos; predomínio do intemperismo físico e ação pluvial; pouca energia da ação fluvial; alta deposição de sedimentos pelos rios em razão do baixo poder de entalhe e de escavar vales; presença de cascalheiro, que sugere abandono de terraços pelo rio quando esse tinha maior capacidade em climas úmidos pretéritos. Por isso, a capacidade de erosão linear é baixa ante a intermitência sazonal dos cursos hídricos, justificando a pequena amplitude topográfica entre os interflúvios e os fundos dos vales.

$\mathrm{Na}$ planície litorânea existem lagoas nas proximidades de várzeas e entre os cordões arenosos. Nos tabuleiros costeiros encontram-se lagoas nas depressões dos glacis de acumulação formando, comumente, planícies fluviolacustres usadas para pesca, dessedentação, lavagem de animais, plantios de várzeas com hortaliças, além do agroextrativismo de frutíferas. Em relação aos usos da água das comunidades pré-litorâneas, desempenham função próxima as dos açudes, verificados os sertões.

Nos maciços as coleções hídricas são exíguas ou inexistentes, restringindo-se praticamente às planícies alveolares com depósitos coluvioaluvionares, promovendo condições mais favoráveis ao uso agrícola, em detrimento das vertentes de acentuadas declividades. São ambientes agradacionais que contêm rios e riachos que abastecem de água as comunidades locais e servem para irrigação de frutas e legumes. Qual o caso do barramento do riacho Bom Jesus, que verte para o manancial de abastecimento da cidade de Meruoca, o açude Frecheiras, com estética ambiental bem conservada.

As irregularidades pluviométricas agravam os problemas dos rigores climáticos, ocasionando secas sazonais e diminuição do volume das coleções hídricas em superfície e de subsuperfície, afetando as atividades nos setores agrossocioeconômicos (campos cultivados com desenvolvimento agrossilvipastoril) e as atividades pesqueiras. A pobreza regional é agravada em virtude dos recursos hídricos constituírem forte esteio socioeconômico e ambiental. Pelo contrário, na época de grandes chuvas, em anos de máxima precipitação, os cursos fluviais recebem grandes volumes d'água provocando cheias (elevação do curso d'água em 
seu leito), seguidas de inundações (elevação não comum do nível, ocasionando transbordamentos) espasmódicas com picos sucessivos, o que provoca transtornos no meio rural - perda de lavouras - e no meio urbano, acometendo áreas de risco, arrombando reservatórios indistintamente.

Considera Souza (2000) que, em termos morfodinâmicos, os interflúvios sertanejos têm implicações que devem ser consideradas no fluxo hidrológico, pois os sedimentos provenientes da erosão diferencial são carreados por escoamento difuso (no sentido lateral e não vertical) e em lençol (sheetflood) para os fundos de vales, agravando as cheias, prejudicando as vazantes, provocando transtorno para as cidades ribeirinhas. O perfil longitudinal dos rios que drenam as colinas sertanejas é muito raso e tangencia o perfil de equilíbrio. As chuvas torrenciais podem provocar excessivo aumento do volume d'água nos canais, pressionando os baixos vales através de transbordamentos laterais. As águas atingem os terrenos aluviais e hidromórficos do leito maior dos rios, acentuando-se o problema quanto maior seja a hierarquia da drenagem, ao receberem tributários de ordens iniciais.

Esses problemas são agravados pelas mudanças diretas e indiretas nos canais de drenagens, conforme explica Ebisemiju (1989). Contudo, esses aspectos confirmam a irregularidade pluviométrica que caracteriza o regime hidrológico estudado, com rios intermitentes, em que há retardos, antecipações, escassez ou concentrações convectivas das chuvas.

\section{Dinâmica hidrológica}

Dentre outros fatores, o ciclo hidrológico em uma bacia relaciona a pluviometria, a permanência em superfície, o alcance dos talvegues, o escoamento superficial difuso, o runnoff, a alimentação hidrogeológica e as perdas por evaporação. O ciclo hidrológico da bacia em causa, entretanto, é dinâmico e as águas em seus três estados - líquido, sólido e gasoso - é renovada espaço-temporalmente através de um sistema de circulação global (BATCHELOR; WALLACE, 1995; NASCIMENTO, 2013). As águas precipitadas, em parte evaporam ou evapotranspiram; outro montante escoa pronta e superficialmente, indo ter com os veios fluviais; e, finalmente, a última quantidade d'água se infiltra nos exíguos aquíferos de forma lenta no subsolo, recarregando as águas de subsuperfície. Segundo Filho (1994), quando os aquíferos são costeiros as águas atingem o nível de base; quando são continentais ou interioranos, este movimento forma o 
escoamento de base que se acrescenta ao escoamento superficial. No conjunto formam o escoamento total dos rios ou escoamento fluvial.

Nos anos de secas o escoamento superficial é cerceado, ficando a perenidade restrita às áreas nas quais o regime de armazenamento/ escoamento é artificialmente controlado. Isto ocorre nos seguintes leitos perenizados: em Tamboril, com o açude Carão; à jusante do açude Araras; à jusante do açude Edson Queiroz e com o açude Jaibaras, até a foz do rio. Neste percurso, do médio ao baixo vale, ocorrem alimentações perenes por outros açudes, como o Arrebita, o Acaraú-Mirim e o São Vicente.

Conforme Ab'Saber (1974) os rios são intermitentes em razão, quase exclusivamente, da alimentação das sub-bacias hidrográficas. Ao tempo que essa intermitência dura anos, com o advento de um ano árido os rios assumem um comportamento de cursos d'água esporádicos do tipo ueds flash food, correspondendo a um típico caráter de rios desérticos. No entanto, a drenagem não chega a conformar um padrão arreico, o que equivaleria a uma drenagem sem estruturação, como se verifica nos desertos quentes com a atividade dunária intensa (CUNHA, 2001). Assim, para a geomorfologia fluvial, a bacia apresenta drenagem organizada, fugindo às características e intensificação da dinâmica sedimentar areolar formadora de dunas, com exceção ao litoral.

Diz Nascimento (2003) que os cursos d'água desempenham funções específicas dentro de cada ecossistema, em vista da semiaridez climática. Os rios, riachos e lagoas propiciam a formação de vegetação ribeirinha, diminuindo a requeima foliar e a caduciofolia através de um feedback de diminuição da evaporação e evapotranspiração e, do manuseio da biodiversidade. Além disso, para o diagnóstico do meio físico de bacias hidrográficas (BELTRAME, 1994) as condições climáticas, a natureza dos terrenos, os aspectos morfopedológicos, os geobotânicos e os de uso/ocupação do solo, influenciam diretamente os recursos hídricos de superfície. $\mathrm{O}$ escoamento fluvial e as reservas terrestres implicantes na dinâmica ecossistêmica que formam os geossistemas/geoambientes são, portanto, influenciados (Quadro 1). São alguns dos aspectos ambientais que necessitam de observação no planejamento dos recursos hídrico.

Como destacou Cunha (1995), mudanças significativas em qualquer desses elementos podem ocasionar efeitos e/ou impactos à jusante da bacia, bem como nos fluxos energéticos de output ou input de sólidos e substâncias dissolvidas, que em função da escala ou intensidade, dos tipos de leitos e de canais, a morfologia da drenagem pode ser modificada. 
O escoamento fluvial com alimentação irregular e deficiente apresenta pequena capacidade de entalhe. Como consequências desse entalhe ocorrem amplitudes altimétricas insignificantes entre os interflúvios e os fundos de vales. Os rios, em grande parte, apresentam gradientes pouco inclinados e perfis transversais com vertentes planas ou ligeiramente côncavas. Sua rede potamográfica é reflexo direto das condições mesoclimáticas. Por isso nas secas os rios "cortam", com exceção dos leitos perenizados dos rios mencionados. $\mathrm{O}$ arranjo, em planta, do rio Acaraú e principais tributários, condiz com os padrões de drenagem com distribuição espacial do seguinte modo: dendrítica ou arborescente, retangular dendrítica (atribuída aos fenômenos tectônicos), paralela, anastomosada ou cataclinal. O sistema hidrográfico do Acaraú apresenta características de drenagem intermitente sazonal exorreica, típica de região semiárida intertropical.

\begin{tabular}{|c|c|}
\hline Elementos & Implicações \\
\hline Clima & $\begin{array}{l}\text { Distribuição espacial do volume da frequência de chuvas, renovação das } \\
\text { reservas hídricas, temperaturas e evapotranspiraçãa. Influências sobre o } \\
\text { balanço hídrico. }\end{array}$ \\
\hline $\begin{array}{l}\text { Natureza do } \\
\text { terreno e } \\
\text { litotipos }\end{array}$ & $\begin{array}{l}\text { Condições geológicas e das formações superficiais, em terrenos } \\
\text { impermeáveis, favorecem o adensamento dos cursos d'água e das depressões } \\
\text { lacustres, evaporação. Com zonas permoporosas, a alimentação do lençol } \\
\text { freático é favorecida. }\end{array}$ \\
\hline $\begin{array}{c}\text { Geologia } \\
\text { Geomorfologia }\end{array}$ & $\begin{array}{l}\text { Processos de escoamento. Características dos perfis longitudinais e } \\
\text { transversais dos rios e vales. Velocidade do escoamento ou retenção, } \\
\text { capacidade de incisão para escavar vales e competência das condições de } \\
\text { transporte de sedimentos e detritos, estão associados ao relevo, sua } \\
\text { topografia e níveis de declividade. }\end{array}$ \\
\hline \begin{tabular}{|c} 
Unidades \\
Vegetacionais
\end{tabular} & $\begin{array}{l}\text { Papel protetor das formações superficiais. Uma maior ou menor densidade } \\
\text { vegetacional, em sequência, magnificam ou atenuam o escoamento } \\
\text { superficial nos interflúvios com vegetação densa influenciando o efeito } \\
\text { splash e o escoamento. Menor cobertura vegetacional no meio urbano } \\
\text { provoca mudanças microclimáticas. }\end{array}$ \\
\hline
\end{tabular}


Uso/ocupação da terra
Efeitos ambientais, diretos e indiretos, no exutório podem ser assinalados diretamente: a retificação, a dragagem do rio e os barramentos indevidos alteram as condições naturais. Concorrem para as mudanças indiretas: o desmatamento, a impermeabilização de superfícies e as mudanças no uso da terra. Áreas impermeabilizadas favorecem o escoamento. No meio urbano, a lavagem de superfícies carreia poluentes líquidos e sólidos. No meio rural, os agrotóxicos e o decapeamento vegetal comprometem a recarga de aquíferos. Esses fatores em conjunto podem provocar modificações nas propriedades físicas e estruturais dos solos, na precipitação e temperatura.

Quadro 1 - Ambiente biofísico: atributos geoambientais incidentes sobre os recursos hídricos superficiais.

Nos sertões, o padrão de drenagem apresenta geometria dendrítica a subdentrítica de textura aberta, é fortemente controlado por fatores estruturais sob efeito de fraturamentos, originando modelo atual de vales com orientação geral SE-NW (Rios Macacos, Jacurutu e Groaíras), SW$\mathrm{NE}$ (Jaibaras) até desembocarem no exutório. Este, por sua vez, segue de $\mathrm{S}$ - com pequena inclinação - para NE-N, encontrando o Atlântico. Nos maciços e cristas residuais a drenagem é dendrítica e/ou subdendrítica fechada, predominantemente pinada, formando canais retilíneos e entrelaçados de quando em quando, originando meandros com declinação inferior a $5^{\circ}$ de declividade (3-8\%). A depender da altitude e expressão areal, passam a exibir brejos de cimeira em suas vertentes de barlavento. Segundo Souza (2000) esse padrão de drenagem colabora para a intensificação da dissecação do relevo em feições colinosas convexas.

No pré-litoral a drenagem tem canais paralelos nos tabuleiros - com declínio discreto para oeste -, e é anastomosada na planície fluviomarinha (litoral). Nas coberturas sedimentares da Ibiapaba a drenagem é cataclinal, com leve caimento topográfico para nordeste.

As chuvas, atingido a superfície, tendem a escoar e se infiltrarem. Ao escoar, como nos terrenos impermeáveis ou de pouca porosidade dos sertões, alimentam o escoamento e vertem para os talvegues. Assim, a hierarquia das drenagens é adensada em ordens de grandeza. Em parte, a água que não escoa e não evapora ou evapotranspira retém-se no solo ou percola, alimentando o lençol freático conforme as variações faciológicas dos solos.

Os rios do Nordeste em determinadas épocas do ano atingem o mar, se tratando de um dos fatores de originalidade dos sistemas hidrográficos e 
hidrológicos regionais que, ao contrário de outras regiões semiáridas do mundo nas quais drenagens convergem para depressões fechadas, os rios dessa região lançam-se no Atlântico. Por isto, na região da referida bacia, os rios são de caráter intermitente com drenagem exorreica que, em grande escala, não permite a formação de solos originalmente salinos, principalmente nas vertentes e interflúvios. Os sais dissolvidos da litologia cristalina - predominante na mesoestrutura - e aqueles provenientes das chuvas carregadas de águas evaporadas do oceano unem-se ao nível de base após arraste pelo fluxo hídrico das torrentes.

Pela capacidade de erosão, transporte e deposição, ademais, os rios são os principais agentes transformadores da paisagem, modelando o relevo (RICOMINI, 2003). Neste contexto, processos fluviais como processos aluviais - compreendendo a erosão, transporte e sedimentação em leques aluviais e rios -, ajudam a explicar a ocorrência de minérios como o urânio. Os depósitos aluviais podem hospedar este minério pois formam os leques aluviais, que são "sistemas fluviais distributários espraiados por dispersão radial no assoalho de uma bacia a partir dos locais de saída de drenagem, confinadas em regiões montanhosas" (RICCOMINI, 2003: 192); sendo que, o depósito mineral é uma função da evolução geológica da área na qual ele se dá. Assim, sedimentação, intemperismo, metamorfismo, vulcanismo e plutonismo são os processos geológicos mais comuns na origem de um depósito mineral (BITTENCOURT, 2003).

Em termos qualitativos as características da rede de drenagem, segundo Oliveria e Ferreira (2001), podem ser definidas através de particularidades chamadas fundamentais ou qualitativas. Observamos, dentre outros aspectos, relevo acidentado pela assimetria das vertentes, influências tectônicas-rupturais na orientação da drenagem e forte integração dos canais de drenagem, colaborando para um desenho, em planta, da rede de drenagem de muitas ramificações.

O quadro seguinte apresenta características qualitativas que, grosso modo, podem ser observadas nas bacias hidrográficas intermitentes sazonais que drenam o Nordeste Setentrional, pelo menos nas porções de terrenos cristalinos do Complexo Nordestino como primazia do piso regional/geológico. Em específico, o quadro traz caracterizações da bacia do rio Acaraú.

Desta forma, o quadro na sequência generaliza as características naturais dos vales fluviais da bacia do Acaraú. 


\begin{tabular}{|c|c|c|}
\hline $\begin{array}{c}\text { Características } \\
\text { qualitativas }\end{array}$ & Descrição & $\begin{array}{c}\text { Respostas qualitativas da } \\
\text { rede de drenagem }\end{array}$ \\
\hline Grau de integração & $\begin{array}{l}\text { Caminho dos canais entre } \\
\text { dois pontos. Quanto mais } \\
\text { curto o caminho maior a } \\
\text { integração. }\end{array}$ & $\begin{array}{l}\text { Não integrada - os canais não se } \\
\text { ligam ( ) } \\
\text { ePouco integrada - poucos canais se } \\
\text { sligam ( ) } \\
\text { alintegrada - todos os canais se } \\
\text { ligam }(\mathbf{X}) \\
\text { Geralmente são integradas, pois } \\
\text { todos os canais se ligam. }\end{array}$ \\
\hline Grau de uniformização & $\begin{array}{l}\text { Repetição das formas da rede } \\
\text { de drenagem num curto } \\
\text { espaço }\end{array}$ & $\begin{array}{l}\text { eNão uniforme ( ) } \\
\text { opuco uniforme ( ) } \\
\text { Uniforme (X) }\end{array}$ \\
\hline Orientação & $\begin{array}{l}\text { Direção predominante dos } \\
\text { drenos }\end{array}$ & $\begin{array}{l}\text { São orientada ( ) } \\
\text { Pouco orientada ( ) } \\
\text { Fortemente orientada }(\mathbf{X})\end{array}$ \\
\hline Grau de controle & $\begin{array}{l}\text { Fatores que alteram o sentido } \\
\text { da drenagem }\end{array}$ & $\begin{array}{l}\text { Não controlada }(\text { ) } \\
\text { Controlada }(\mathbf{X}) \\
\text { Altamente controlada }(\text { ) }\end{array}$ \\
\hline Angularidade & $\begin{array}{|llll|}\begin{array}{l}\text { Mudança } \\
\text { leitos }\end{array} & \text { na direção dos } \\
\end{array}$ & $\begin{array}{l}\text { Saixa }(\mathbf{X}) \\
\text { Média ( ) } \\
\text { Alta angularidade ( ) }\end{array}$ \\
\hline Ângulos de juntura & $\begin{array}{l}\text { Ângulo formado na foz de } \\
\text { um tributário com seu } \\
\text { receptor }\end{array}$ & $\begin{array}{l}\text { e Reto (X) } \\
\text { Agudo ( ) } \\
\text { Muito Agudo ( ) }\end{array}$ \\
\hline Simetria das vertentes & $\begin{array}{l}\text { Correspondência em } \\
\text { grandeza, forma e orientação } \\
\text { relativa }\end{array}$ & $\begin{array}{l}\text { Simétrica ( ) } \\
\text { Assimétrica (X) }\end{array}$ \\
\hline
\end{tabular}

Quadro 2 - Características qualitativas da bacia de drenagem do Acaraú.

Fonte: Adaptado com base em Oliveira e Ferreira (2001).

Uma caracterização hidrológica mais rica passa por apreciação genérica da geomorfologia fluvial regional no que se refere a características naturais dos rios e canais. Neste sentido, além dos tipos de padrão de drenagem, escoamento e sua gênese na bacia, o vale fluvial pode ser entendido à luz dos tipos de leitos e dos tipos de canais, como orienta (CUNHA, 2003); já que, cada uma dessas fisionomias apresenta uma dinâmica peculiar das águas correntes, associadas a uma geometria hidráulica específica originada pelos processos erosivos, de transporte hidrossedimentológico e agradacionais. Observemos o Quadro 3. 


\begin{tabular}{|c|c|c|c|c|c|}
\hline \multirow{2}{*}{$\begin{array}{l}\text { Bacias de } \\
\text { drenagem }\end{array}$} & \multirow{2}{*}{$\begin{array}{l}\text { Tipo de } \\
\text { leito }\end{array}$} & \multirow[b]{2}{*}{ Tipo de canais } & \multicolumn{3}{|c|}{ Tipo de padrão de drenagem } \\
\hline & & & $\begin{array}{c}\text { Em função do } \\
\text { Escoamento }\end{array}$ & $\begin{array}{c}\text { Em função da } \\
\text { Gênese }\end{array}$ & $\begin{array}{c}\text { Em função da } \\
\text { Geometria }\end{array}$ \\
\hline $\begin{array}{l}\text { Bacia do } \\
\text { Acaraú }\end{array}$ & $\begin{array}{c}\text { Leito menor, } \\
\text { de vazante, } \\
\text { maior } \\
\text { excepcional }\end{array}$ & $\begin{array}{l}\text { Meandrante, } \\
\text { anastomosado } \\
\text { na planície } \\
\text { fluviomarinha }\end{array}$ & Exorreica & $\begin{array}{c}\text { Consequente, } \\
\text { obsequente, } \\
\text { subsequente }\end{array}$ & $\begin{array}{c}\text { Dendrítica e } \\
\text { subdendrítica } \\
\text { (médio e alto } \\
\text { curso), paralelo } \\
\text { (baixo curso) }\end{array}$ \\
\hline $\begin{array}{c}\text { Principais } \\
\text { Sub- } \\
\text { bacias: } \\
\text { Macacos, } \\
\text { Groaíras, } \\
\text { Jacurutu e } \\
\text { Jaibaras }\end{array}$ & $\begin{array}{c}\text { Leito menor, } \\
\text { de vazante, e } \\
\text { maior } \\
\text { excepcional }\end{array}$ & $\begin{array}{c}\text { Retilíneo } \\
\text { parealelo e } \\
\text { meandrante } \\
\text { irregular }\end{array}$ & Endorreica & $\begin{array}{c}\text { Consequente, } \\
\text { obsequente, } \\
\text { subsequente } \\
\text { insequente }\end{array}$ & $\begin{array}{l}\text { Dendrítica, } \\
\text { subdendrítica }\end{array}$ \\
\hline
\end{tabular}

Quadro 3 - Características naturais dos vales fluviais.

Fonte: Elaborado com base em Cunha (2003).

\section{Gestão de Bacias Hidrográficas e condições hidrogeológicas}

Os elementos qualitativos e as características naturais dos vales fluviais demonstrados, em respectivo, nos últimos quadros são importantes na gestão dos recursos hídricos. Com o açodamento das necessidades humanas, há, progressivamente, a substituição de bens e serviços por suprimentos da mesma ordem, exigindo grandes quantidades de água mas com nova tecnologia e demanda crescente por energia, aumentado o denominado consumo de Produção Primária Líquida (PPL) - recurso alimentar básico a todos os seres que não realizam fotossíntese (MERICO, 1996). Dessa forma, a pressão sobre os recursos naturais é ampliada, ao tempo que serve de insumo às atividades produtivas.

A açudagem no Nordeste, historicamente, é destacada como bordão dentre as melhores saídas ante as vicissitudes semiáridas. Pelo sim, pelo não, a eficiência de reservatórios - sobretudo a dos grandes - é questionável. Em média há uma eficiência hidrológica pífia, com 1/5 ou $20 \%$ do uso ótimo dos açudes que são assolados pela elevada evaporação e balanço hídrico deficitário, concorrendo para um quadro de não-incentivo aos usos múltiplos da água (REBOUÇAS, 1997). 
A título de contextualização, o Programa de Gerenciamento de Águas Territoriais, da Companhia de Gestão dos Recursos Hídricos do Ceará (COGERH), monitora os maiores açudes públicos do Ceará (estaduais e federais), que são em número de 126, com capacidade de armazenamento de 17.787.469,6 bilhões de $\mathrm{m}^{3}$. Neste contexto, da bacia do Acaraú, repleta de pequenos e médios açudes, sobressaem os 12 maiores reservatórios hídricos - com capacidade de armazenamento total de 1.440.263.000 $\mathrm{m}^{3}$-, tendo como principal corpo hídrico o açude Araras, capacitado para armazenar $891.000 .000 \mathrm{~m}^{3}$. Na Tabela 01, a título de ilustração, observa-se que no período de escassez de chuvas o uso ótimo dos açudes é significativamente reduzido - especialmente para o ano de 2014, após três anos consecutivos de secas.

É importante realizar cadastramento dos maiores açudes públicos e privados dessa bacia, gerando banco de dados qualitativo e não só quantitativo, como fez a Companhia de Gestão de Recursos Hídricos para o estado do Ceará. Estes corpos hídricos, a exemplo dos leitos fluviais, que também os alimentam, têm nas chuvas seus principais renovadores. As irregularidades das chuvas influenciam as cotas dos açudes e a capacidade de armazenamento das lagoas.

\begin{tabular}{|c|c|c|c|c|c|c|}
\hline \multirow{2}{*}{ Açude } & \multirow{2}{*}{ Município } & $\begin{array}{c}\text { Capacidade } \\
\text { Total } \\
\mathbf{m}^{\mathbf{3}} \text { milhões }\end{array}$ & \multicolumn{4}{|c|}{ Volume em milhões m3/\% do total } \\
\cline { 5 - 7 } & & $\mathbf{1 1 / 1 9 9}$ & $\mathbf{1 0 / 2 0 0 3}$ & $\mathbf{0 7 / 2 0 0 5}$ & $\mathbf{0 7 / 1 1 / 1 4}$ \\
\hline $\begin{array}{c}\text { Acaraú } \\
\text { Mirim }\end{array}$ & Massapê & 52.000 & $41.618 / 80$ & $\begin{array}{c}46.460 / \\
89,3\end{array}$ & $51.471,988 / 99$ & $12.27 / 30$ \\
\hline $\begin{array}{c}\text { Araras } \\
\text { Norte }\end{array}$ & Varjota & 860.900 & $619.841 / 70$ & $\begin{array}{c}760.970 / \\
85,4\end{array}$ & $\begin{array}{c}690.082,432 / \\
77,5\end{array}$ & $11.14 / 12,5$ \\
\hline Arrebita & Forquilha & 19.600 & $12.497 / 64$ & $\begin{array}{c}12.290 / \\
62,7\end{array}$ & $\begin{array}{c}8.587 .996 / \\
43,8\end{array}$ & $\begin{array}{c}4.940 / \\
25,19\end{array}$ \\
\hline $\begin{array}{c}\text { Ayres de } \\
\text { Souza }\end{array}$ & Sobral & 104.430 & $81.010 / 78$ & $87.780 / 84$ & $85.417,472 / 81,8$ & $3.538 / 3,55$ \\
\hline Bonito & Ipu & 6.000 & $2.382 / 40$ & $3.070 / 51,1$ & $\begin{array}{c}4.175,000 / \\
73,7\end{array}$ & $7.000 / 1,23$ \\
\hline Carão & Tamboril & 26.229 .9 & $15.893 / 61$ & $4.010 / 15,2$ & $16.649,744 / 63,5$ & $1.190 / 4,55$ \\
\hline Carmina & Catunda & 13.628 .1 & - & $800 / 50,8$ & $\begin{array}{c}9.878 .424 / \\
72,5\end{array}$ & $1.100 / 0,84$ \\
\hline $\begin{array}{c}\text { Edson } \\
\text { Queiroz* }\end{array}$ & $\begin{array}{c}\text { Santa } \\
\text { Quitéria }\end{array}$ & 250.500 & $171.900 / 69$ & $153.880 /$ & $\begin{array}{c}197.481 .312 / \\
77,7\end{array}$ & $\begin{array}{c}59.290 / \\
23,34\end{array}$ \\
\hline $\begin{array}{c}\text { Farias de } \\
\text { Sousa }\end{array}$ & $\begin{array}{c}\text { Nova } \\
\text { Russas }\end{array}$ & 12.230 & $3.825 / 31$ & $1.920 / 15,6$ & $\begin{array}{c}5.170 .000 / \\
42,3\end{array}$ & $1.600 / 1,27$ \\
\hline
\end{tabular}




\begin{tabular}{|c|c|c|c|c|c|c|}
\hline Forquilha & Forquilha & 50.130 & $21.301 / 42$ & $\begin{array}{c}37.690 / \\
75,1\end{array}$ & $26.763 .802 / 53,4$ & $4.860 / 9,69$ \\
\hline $\begin{array}{c}\text { São } \\
\text { Vicente }\end{array}$ & $\begin{array}{c}\text { Santana do } \\
\text { Acaraú }\end{array}$ & 9.840 & $5.569 / 57$ & $7.110 / 72,2$ & $\begin{array}{c}7.660 .004 / \\
77,8\end{array}$ & $\begin{array}{c}2.080 / \\
21,13\end{array}$ \\
\hline Sobral & Sobral & 4.675 & $2.481 / 63$ & $\begin{array}{c}3.760 / \\
80,4\end{array}$ & $\begin{array}{c}3.744 .402 / \\
80,1\end{array}$ & $\begin{array}{c}1.340 / \\
31,31\end{array}$ \\
\hline Total & $\mathbf{1 2}$ & $\mathbf{1 . 4 4 0 . 2 6 3}$ & $\mathbf{9 7 8 . 3 1 7 / 6 9}$ & $\begin{array}{c}\mathbf{1 . 1 1 9 . 7 4 0 /} \\
\mathbf{7 7 , 7}\end{array}$ & $\begin{array}{c}\mathbf{1 . 1 0 7 . 3 2 9 , 5 7 9 /} \\
\mathbf{7 6 , 7}\end{array}$ & $\mathbf{1 1 0 , 3 4 8 / 1 3 , 7 1}$ \\
\hline
\end{tabular}

Tabela 1 - Maiores açudes da bacia do Acaraú: situação em 1997, 2003, 2005 e 2013.

Fonte: Souza (1998) e Cogerh (2005). *Açude com capacidade retificada para 254 milhões de $\mathrm{m}^{3}$.

Infere-se da tabela acima que os níveis atuais são críticos, ao tempo que os principais reservatórios analisados estão apenas com uma média de $13,7 \%$ do volume d'água armazenado de toda a bacia. Principalmente nos sertões, nos quais os suprimentos de água são limitados e, como resultado, há baixa produtividade de recursos naturais, a intermitência dos cursos d'água provoca recessão e descarga nula durante os meses de estio que se prolongam ao longo do ano. Por isso é importante a gestão da vazão hídrica dos reservatórios e dos rios durante o ano, principalmente na estação chuvosa, em consonância com a redução de conflitos pelos usos múltiplos da água e pelo acesso à terra. E importante considerar a manipulação da natureza, da agricultura e dos recursos humanos, para atingir objetivos específicos considerando os aspectos social, econômico e institucional dentro de uma bacia hidrográfica, ou quaisquer outras regiões relevantes.

Muitos açudes do Ceará têm baixa eficiência - variando de 1,6\% a $39,4 \%$ - e a média de eficiência está perto de $22,4 \%$, quando deveria alcançar os $90 \%$. Por isso “(...) pagamos, efetivamente, à natureza, um alto 'preço' pela acumulação de água em reservatório de superfície" (VIEIRA, 2002: 513). Por seu turno, o Plano Estadual de Recursos Hídricos diz que sobre o rendimento médio dos açudes estaduais " $\mathrm{R}+25 \%$ ", quer dizer, volume regularizado anual correspondendo a $1 / 4$ da capacidade dos reservatórios, não há estudo específico (FILHO et al., 1994). Os açudes podem, ainda, funcionar mais como "evaporímetros" do que como reservatórios seguros de água, por problemas ou falta de critérios hidrológicos no dimensionamento do barramento.

Infelizmente, esses corpos hídricos são poluídos por sólidos e líquidos nos quais a cor, o cheiro, a turbidez e a presença de macrófitas dão 
sinais empíricos de alterações nas propriedades estéticas, físico-químicas e biológicas das águas acumuladas.

Diante das condições de carência de saneamento básico, da poluição das águas e da presença de estações de tratamento de água (ETA'S), os aquíferos subterrâneos podem se constituir como alternativa ao uso e consumo humano por se encontrarem mais bem protegidos de agentes poluidores; porque as camadas litológicas, que as comportam, podem funcionar como filtro natural.

A água é um dos maiores fatores limitantes da produção e de determinação de áreas secas. Sua falta e desperdício são causas fundamentais de muitos problemas de degradação ambiental e desertificação. Por isso, as considerações hidrológicas são importantes na determinação da magnitude e dos sinais de desertificação - um sério problema que necessita de consideração especial (DRESCH, 1987; PUIGDEFÁBREGAS \& MENDIZABAL, 1998; NASCIMENTO, 2013).

$\mathrm{O}$ potencial hidrogeológico, em grande parcela, constitui reservatórios subterrâneos com dimensões variadas - geralmente não grandes -, contendo volumes de água acumulada que podem remontar às origens de suas formações geológicas. Sua disponibilidade tem o potencial - montante hídrico não usado pelos homens -, podendo acrescer as reservas, se alguma demanda socioeconômica exigir. Desse modo, é que outra opção para obter água para usos múltiplos, preferencialmente o humano, além dos açudes, encontra-se na oferta do potencial hidrogeológico, conforme a permoporosidade e arranjos estruturais dos terrenos e depósitos. Diversos fatores podem favorecer o potencial hidrogeológico dos terrenos, como taxas pluviométricas, solos espessos, cobertura vegetal densa, relevo favorável e padrões de uso e ocupação do solo.

De fundamental importância, as águas dos rios e aquíferos, bem como seus volumes estocados - naturais ou artificiais - formam as reservas móveis de água, ao tempo que podem ser utilizados fora dos locais nos quais caíram as chuvas que os originam (REBOUÇAS, 1997).

A par de balanço hídrico desfavorável, as águas subterrâneas encontram-se mais bem protegidas com uma parcela de perda hídrica consideravelmente menor do que aquela perdida por mananciais de superfície. Os poços (cacimbas) representam fontes de complemento no abastecimento doméstico, industrial ou agrícola, sobretudo diante das consequências da desertificação. Estrategicamente, servem como reservas 
nos períodos críticos de estiagem ou por motivos de segurança. Um melhor aproveitamento da açudagem ocorreria a partir da interação com poços e cisternas para abastecimento d'água, como, ainda, a melhoria dos padrões de qualidade hídrica.

O investimento para captação d'água subterrânea é parcelável. Isto é, ao passo que a demanda aumenta o usuário vai construindo as obras captadoras, adequando os poços ao volume d'água requerido. Deste jeito, é possível trabalhar com um parcelamento de custos e investimentos com uma margem de segurança no que concerne à procura por água. Para o meio rural, além das cisternas de placas, o uso de poços se mostra como a alternativa ao abastecimento de sua população. Mencionamos o fato de que a irrigação é a atividade mais consumidora do recurso hídrico, conforme alerta Filho (1994), nos cenários atuais ou projetados, pelo menos para as próximas décadas.

Com área superficial de influência pequena, no que tange ao impacto ambiental, a perfuração de poços tubulares não provoca maiores modificações no meio físico. Os maiores problemas residem na nãoobediência aos padrões técnicos de alocação e manutenção recomendados para implantação e operação deles.

Ocorrem três tipos de aquíferos, segundo as características geológicas do terreno, com 1756 poços perfurados, predominando os do tipo fissural, pela primazia espacial do substrato cristalino: aluvionar $(10 \%)$, sedimentar (24\%) e fissural (66\%) (Tabela 02). Os aquíferos mais porosos e mais representativos ocorrem em setores em que as rochas apresentam maior capacidade de armazenamento d'água nos espaços intergranulares. São exemplos, as coberturas sedimentares das dunas, aluviões, sedimentos da Formação Barreiras e na Ibiapaba.

Para efeito de gerenciamento de recursos hídricos num contexto emergencial, como é o caso das secas, merece destaque o grau de utilização das fontes de abastecimento de água subterrânea pois esse recurso torna-se significativo no suprimento hídrico da população e dos rebanhos. É de conhecimento geral o fato de que grande quantidade de captações de água subterrânea no semiárido, sobretudo em rochas cristalinas, encontra-se desativada e/ou abandonada, tomando-se por base problemas diversos. Uma parcela poderia voltar a funcionar e aumentar a oferta de água, ante pequenas ações corretivas (CPRM, 1998). Como sabido, grande parte da bacia está sobre embasamento cristalino cujas águas subterrâneas são alimentadas pelas chuvas ou pelos rios, que em 
razão de uma permoporosidade insignificante têm as taxas ínfimas. Ademais, a deficiente alimentação e a falta de exutórios importantes tornam as condições hidrogeológicas mais exíguas.

\begin{tabular}{|c|c|c|c|c|}
\hline Municípios & Aluvionar & Fissural & Sedimentar & Total \\
\hline Acaraú & - & - & 171 & 171 \\
\hline Alcântaras & - & 31 & - & 31 \\
\hline Bela Cruz & - & - & 34 & 34 \\
\hline Cariré & 2 & 76 & - & 78 \\
\hline Catunda & - & 1 & 65 & 66 \\
\hline Cruz & - & - & 53 & 53 \\
\hline Forquilha & - & 41 & - & 41 \\
\hline Graça & 2 & 30 & 2 & 34 \\
\hline Groaíras & 1 & 30 & - & 31 \\
\hline Hidrolândia & 2 & 72 & - & 74 \\
\hline Ipu & 3 & 30 & 11 & 44 \\
\hline Ipueiras & 11 & 55 & 10 & 76 \\
\hline Marco & - & - & 39 & 39 \\
\hline Massapê & - & 96 & - & 96 \\
\hline Meruoca & - & 23 & - & 23 \\
\hline Monsenhor Tabosa & 50 & 47 & - & 97 \\
\hline Morrinhos & 17 & 1 & 36 & 54 \\
\hline Mucambo & 6 & 11 & - & 17 \\
\hline Nova Russas & 4 & 58 & - & 62 \\
\hline Pacujá & - & 28 & - & 28 \\
\hline Pires Ferreira & - & 31 & - & 31 \\
\hline Reriutaba & - & 19 & - & 19 \\
\hline Santa Quitéria & 16 & 144 & - & 160 \\
\hline Santana do Acaraú & 16 & 44 & - & 60 \\
\hline Sobral & 4 & 202 & - & 206 \\
\hline Tamboril & 40 & 91 & - & 131 \\
\hline Total & $\mathbf{1 7 4}$ & $\mathbf{1 . 1 6 1}$ & $\mathbf{4 2 1}$ & $\mathbf{1 7 5 6}$ \\
\hline
\end{tabular}

Tabela 2 - Poços por tipo de aquíferos.

Fonte: CPRM (1998).

O município com o maior número de poços é Sobral (206), tendo $11,73 \%$, e o com menor número é Mucambo, com 0,96\%. Apenas Graça, Morrinhos, Ipu e Ipueiras detêm poços nas três variações de terrenos encontrados, possuindo, respectivamente 34, 54, 44 e 76 perfurações. Alcântaras apresenta a menor variação, com um poço perfurado somente em terreno fissural. Em Sobral, a CPRM (1998) calculou apenas a vazão 
média do domínio das rochas cristalinas, que compreendem $90 \%$ das captações de água subterrânea, considerando que há vazão média de 1,7 $\mathrm{m}^{3} / \mathrm{h}$ (Tabela 03) - resultado de uma análise estatística de mais de 3.000 poços no cristalino.

Sobre a estimativa de disponibilidade hidrogeológica, a próxima tabela considera 115 poços tubulares em uso no cristalino, com uma produção atual da ordem de $195,5 \mathrm{~m}^{3} / \mathrm{h}$ - sendo $35,7 \mathrm{~m}^{3} / \mathrm{h}$ provenientes de poços públicos e $159,8 \mathrm{~m}^{3} / \mathrm{h}$, de poços privados. Segundo a CPRM (1998), caso fosse implantada política de recuperação e/ou instalação dos poços atualmente sem uso estima-se um aumento da ordem de $62 \%\left(120,7 \mathrm{~m}^{3} / \mathrm{h}\right)$, relacionado à atual oferta d'água subterrânea. Deste montante, cerca de $54,5 \mathrm{~m}^{3} / \mathrm{h}(28 \%)$ seriam provenientes de poços públicos. O nível hidrostático do exutório tem profundidade aproximadamente de 5 metros, possibilitando a exploração do lençol freático por cacimbas e poços durante as secas. Este nível, todavia, poderá estar sendo rebaixado em função do decapeamento vegetal e ablação de solos, barramentos indevidos e outras mudanças ambientais.

\begin{tabular}{|c|c|c|c|c|c|c|c|}
\hline \multirow[t]{2}{*}{$\begin{array}{c}\text { Poços } \\
\text { Tubulares }\end{array}$} & \multicolumn{3}{|c|}{\begin{tabular}{|c|} 
Estimativa da \\
Disponibilidade \\
Instalada Atual
\end{tabular}} & \multicolumn{4}{|c|}{$\begin{array}{c}\text { Estimativa da } \\
\text { Disponibilidade Instalada } \\
\text { Potencial }\end{array}$} \\
\hline & \begin{tabular}{|c|} 
Em \\
Uso
\end{tabular} & 2unit. & $\mid \begin{array}{c}Q_{\mathrm{e}} \\
\text { Total } \\
\left(\mathbf{m}^{3} / \mathbf{h}\right)\end{array}$ & \begin{tabular}{|} 
Desativados/ \\
Não \\
Instalados
\end{tabular} & $\begin{array}{l}\text { Qeunit. } \\
\left(\mathbf{m}^{3} / \mathbf{h}\right)\end{array}$ & $\mid \begin{array}{c}\mathbf{Q}_{\mathrm{e}} \\
\text { Total } \\
\left(\mathbf{m}^{3} / \mathbf{h}\right)\end{array}$ & $\begin{array}{c}\text { \% de aumento da } \\
\text { disponibilidade atual }\end{array}$ \\
\hline Públicos & 21 & 1,7 & 35,7 & 32 & 1,7 & 54,4 & 28 \\
\hline Privados & \begin{tabular}{l|l|}
94 & \\
\end{tabular} & 1,7 & \begin{tabular}{|l|}
159,8 \\
\end{tabular} & 39 & 1,7 & \begin{tabular}{|l|}
66,3 \\
\end{tabular} & 34 \\
\hline Total & 115 & - & 195,5 & 71 & - & 120,7 & 62 \\
\hline
\end{tabular}

Tabela 3 - Estimativa da disponibilidade instalada atual e potencial das rochas cristalinas em Sobral.

Fonte: CPRM (1998).

Quando se perfura uma zona cisalhada ou alterada em contato com aluviões pode haver reservas produtivas aluviais. Certo é que a alimentação de lençóis é mais efetiva à medida que haja coincidência com fraturas ou falhas com o encaixe fluvial, demonstrando, neste caso, drenagem controlada por marcas tectônicas, o que leva a concluir que a alimentação 
dos aquíferos fraturados está imbricada aos eixos da drenagem superficial (SOUZA, 1998, 2000).

Com tudo isto, o Polígono das Secas - que tem $70 \%$ do seu substrato constituído de rochas cristalinas - tem um quadro de águas subterrâneas desfavorável, quer seja em quantidade, quer em qualidade (NASCIMENTO, 2013). De forma geral, as águas subterrâneas do domínio cristalino são limitadas, restringindo-se às zonas fraturadas e manchas aluviais. A vazão média em poços tubulares no cristalino fraturado é ínfima, com $5 \mathrm{~m} 3 / \mathrm{h}$; e salinidade média da ordem de $2 \mathrm{mil} \mathrm{mg/l}$. Diante da falta de fiscalização às atividades de perfuração e uso de poços, estima-se que no Nordeste brasileiro existem aproximadamente $50 \mathrm{mil}$, sendo que pouco mais de 20 mil estão em operação, por motivos técnicos e/ou políticos (REBOUÇAS, 1997).

A capacidade de armazenamento d'água subterrânea é fornecida por arranjos estruturais localizados nos contatos geológicos (por falhas e no manto de alteração). As fissuras e fraturas, como porosidade secundária na qual a água circula, apresentam condutibilidade hidráulica não com base em porosidade primária das rochas, como no caso de aquíferos clásticos, mas pelos efeitos dos componentes estruturais alimentados por precipitação atmosférica, rede hidrográfica e aluviões.

No domínio do Complexo Nordestino as exceções, portanto, estão associadas às zonas de alterações e fraturadas. Nesse caso o intemperismo físico não é um possibilitador adequado para o pleno desenvolvimento de mantos de alteração, ao passo que as condições mais exequíveis estão em áreas submetidas a tectonismo, podendo armazenar água nas zonas fissuradas em contato com a rocha-mãe. Tais fissuras ainda são submetidas a processos constantes de colmatagem, sendo obstruídas, sobretudo, por conta da remoção de detritos intemperizados, o que também, contribui para tornar as reservas inexpressivas (SOUZA, 2000). No entanto, a alimentação é irregular, o que pode ser comprovado piezometricamente.

Embora os terrenos cristalinos tenham baixa capacidade de armazenamento, é neste domínio onde se concentra o maior número de poços dada a sua maior dimensão espacial, com 1.126 unidades ou $66 \%$ do total. Sobral tem o maior número de perfurações (202), seguido por Santa Quitéria (144) e Massapê com (96). Acaraú, Bela Cruz, Cruz e Marco não apresentam terrenos cristalinos, por isto, não registram a ocorrência de poços fissurais. Os depósitos aluvionares, em sua maioria, constituem boa alternativa como manancial porque têm alta potencialidade hidrogeológica. 
Encontram-se restritos às planícies fluviais e são constituídos por sedimentos arenoargilosos cenozóicos, de pequena espessura e com capacidade em função da alta permeabilidade litológica. Correspondem apenas a $10 \%$ dos poços perfurados, num total de 174. Monsenhor Tabosa se destaca pela quantidade desses poços (50) seguida por Tamboril (40), mas há municípios que não os apresentam, a exemplo de Acaraú, Meruoca e Reriutaba. Os alúvios representam recursos tanto mais importantes quanto mais eficaz for a gestão dos reservatórios. Não obstante a função de regularização das aluviões deve indubitavelmente ser considerada (REBOUÇAS, 1997). As águas subterrâneas nesses setores devem ser buscadas e utilizadas desde que as condições naturais estejam isentas de organismos patógenos e sem maiores alterações de turbidez, cor, cheiro e sabor. Os tipos de aquíferos e suas principais características estão reunidos no quadro abaixo.

Historicamente, ao longo dos vales com seus depósitos aluvionares ocorrem as maiores ocupações urbanas, como Santa Quitéria, Sobral e Acaraú. Com permeabilidade elevada dos sedimentos arenosos das aluviões, há possibilidades de se conseguir vazões expressivas em captações de poços rasos e de baixo custo para instalação urbana e implantação de irrigação. Sem dúvidas, é nos terrenos sedimentares onde há maior produtividade de água subterrânea. A porosidade das rochas originárias e a permeabilidade do terreno foram alguns dos atrativos para se perfurarem 421 poços cuja maior quantidade, representando $23,9 \%$, está em Acaraú (171). Em seguida vem Catunda, com 65 poços.

\begin{tabular}{|c|c|c|c|}
\hline Aquífero & Potencialidade & Limitações & Ocorrências \\
\hline $\begin{array}{l}\mathbf{A} \\
\mathbf{L} \\
\mathbf{U} \\
\mathbf{V} \\
\mathbf{I} \\
\mathbf{O} \\
\mathbf{N} \\
\mathbf{A} \\
\mathbf{R}\end{array}$ & $\begin{array}{l}\text { Bons aspectos qualiquantitavos das } \\
\text { águas. Facilidade de recarga com } \\
\text { elevada taxa de renovação. } \\
\text { Normalmente, a alta permeabilidade } \\
\text { dos terrenos arenosos compensa as } \\
\text { pequenas espessuras, produzindo } \\
\text { vazões significativas. Águas de fácil } \\
\text { captação, com boa distribuição e } \\
\text { frequência no cristalino. } \\
\text { Observação de condições sanitárias } \\
\text { adequadas para o suprimento de } \\
\text { demandas, sobretudo nas áreas }\end{array}$ & \begin{tabular}{|l|} 
Pequena espessura \\
das aluviões, com \\
ocorrência limitada \\
aos leitos fluviais. \\
Em grande parte há \\
um pequeno número \\
de poços funcionando \\
adequadamente.
\end{tabular} & $\begin{array}{l}\text { Várzeas dos grandes } \\
\text { cursos d'água, } \\
\text { municípios de: } \\
\text { Cariré, Graça } \\
\text { Groaíras, Hidrolândia, } \\
\text { Monsenhor Tabosa, } \\
\text { Morrinhos, Mucambo, } \\
\text { Nova Russas, Santa } \\
\text { Quitéria, Santana do } \\
\text { Acaraú, Sobral, Ipu, } \\
\text { Iipueiras, Tamboril e } \\
\text { Varjota }\end{array}$ \\
\hline
\end{tabular}




\begin{tabular}{|c|c|c|c|}
\hline & sotopostas ao cristalino. & & \\
\hline $\begin{array}{c}\mathbf{S} \\
\mathbf{E} \\
\mathbf{D} \\
\mathbf{I} \\
\mathbf{M} \\
\mathbf{E} \\
\mathbf{N} \\
\mathbf{T} \\
\mathbf{A} \\
\mathbf{R}\end{array}$ & $\begin{array}{l}\text { Bom potencial com forte indicação } \\
\text { ao suprimento da demanda, } \\
\text { principalmente para o semiárido. } \\
\text { As águas geralmente apresentam } \\
\text { boa qualidade, com recarga } \\
\text { facilitada. Com áreas extensas, } \\
\text { implica numa maior capacidade de } \\
\text { armazenamento. } \\
\text { Os sedimentos da Formação Serra } \\
\text { Grande são constituídos } \\
\text { principalmente por arenitos } \\
\text { grossos a conglomeráticos que, } \\
\text { normalmente, apresentam } \\
\text { potencial quantitativo e qualitativo } \\
\text { médio. }\end{array}$ & $\begin{array}{l}\text { Espessura } \\
\text { significativa das } \\
\text { formações, que às } \\
\text { vezes indica grande } \\
\text { profundidade dos } \\
\text { poços, onerando a } \\
\text { captação. Restritos às } \\
\text { áreas sedimentares, } \\
\text { que são bem menos } \\
\text { expressivas que as } \\
\text { áreas cristalinas. A } \\
\text { quantidade de poços } \\
\text { instalados não } \\
\text { corresponde ao } \\
\text { número daqueles em } \\
\text { funcionamento. } \\
\text { Variações } \\
\text { faciológicas com } \\
\text { intercalações de } \\
\text { níveis mais e menos } \\
\text { permeáveis, induzem } \\
\text { potencialidades } \\
\text { diferenciadas. As } \\
\text { coberturas } \\
\text { sedimentares } \\
\text { coluviais } \\
\text { compreendem } \\
\text { manchas isoladas de } \\
\text { sedimentos detríticos } \\
\text { que, em função das } \\
\text { espessuras bastante } \\
\text { reduzidas, têm pouca } \\
\text { expressão como } \\
\text { mananciais. }\end{array}$ & \begin{tabular}{|l|} 
Tabuleiros pré- \\
litorâneos da \\
Formação Barreiras e \\
Formação Serra \\
Grande no Planalto da \\
Ibiapaba. Abrange os \\
Municípios de \\
Morrinhos, Marco, \\
Graça, Cruz, Bela \\
Cruz, Acaraú, \\
Catunda, Cariré, Ipu e \\
Iipueiras.
\end{tabular} \\
\hline
\end{tabular}




\begin{tabular}{|c|c|c|c|}
\hline $\begin{array}{l}\mathbf{F} \\
\mathbf{I} \\
\mathbf{S} \\
\mathbf{S} \\
\mathbf{U} \\
\mathbf{R} \\
\mathbf{A} \\
\mathbf{L}\end{array}$ & $\begin{array}{l}\text { Cobrem a maior parte do território } \\
\text { estadual e da bacia. Reservas } \\
\text { estratégicas para a região } \\
\text { semiárida, como importante } \\
\text { alternativa de abastecimento em } \\
\text { casos de pequenas comunidades ou } \\
\text { como reserva estratégica em } \\
\text { períodos prolongados de estiagem. }\end{array}$ & \begin{tabular}{|l|} 
Não existe \\
porosidade primária, \\
ocorrência de água \\
condicionada por \\
porosidade \\
secundária (fraturas e \\
fendas). \\
Reservatórios \\
aleatórios, \\
descontínuos e de \\
pequena extensão. \\
Vazões pequenas e a \\
água, em função da \\
falta de circulação e \\
dos efeitos do clima \\
semiárido é, na maior \\
parte das vezes, \\
salinizada. Baixo \\
potencial, com fortes \\
limitações para suprir \\
a demanda existente.
\end{tabular} & $\begin{array}{l}\text { Terrenos do } \\
\text { embasamento } \\
\text { cristalino, dep. } \\
\text { sertaneja e maciços } \\
\text { residuais. Verificados } \\
\text { em Alcântaras, Cariré, } \\
\text { Catunda, Forquilha, } \\
\text { Groaíras, Graça, } \\
\text { Hidrolândia, Massapê, } \\
\text { Meruoca, Monsenhor } \\
\text { Tabosa, Morrinhos, } \\
\text { Mucambo, Nova } \\
\text { Russas, Pacujá, } \\
\text { Reriutaba, Santa } \\
\text { Quitéria, Santana do } \\
\text { Acaraú, Sobral, } \\
\text { Tamboril, Varjota, } \\
\text { Ipu, Ipueiras e Pires } \\
\text { Ferreira. }\end{array}$ \\
\hline
\end{tabular}

Quadro 4 - Aquíferos e suas características.

Fonte: CPRM (1998).

\section{Considerações finais}

Pari-passo, Quantidade, Qualidade e Garantia (QQG) das reservas hídricas superficiais e subsuperficiais nas bacias hidrográficas semiáridas do Brasil, com destaque para a bacia do Acaraú, são mais comprometidas por conta da demanda por água e, principalmente, pela ocupação desordenada do ambiente biofísico, ou pela construção de poços sem critérios técnicos de alocação. A retirada do substrato do leito e das margens fluviais, os desmatamentos para o uso agrícola, o extrativismo lenhoso, o barramento de córregos e o lixo em decomposição em seções dos rios - principalmente nas proximidades das cidades -, diminuem o volume dos veios fluviais e assoreiam os corpos hídricos. Neste espectro, a desertificação - ao passo que é a maior consequência da degradação ambiental em áreas semiáridas e subúmidas secas - é uma forte e real ameaça em todas as bacias do Nordeste Setentrional. 
Convém registrar que sobre as doenças provocadas pelos problemas de saneamento ambiental, a relação entre água e saúde pública é estreita. Quando as águas em quantidades são insuficientes para higiene pessoal e/ou estão contaminadas, podem provocar doenças. Esse panorama é agravado durante a época das férias e festas culturais ou religiosas, feriados prolongados e finais de semana, quando os lugares turísticos recebem uma quantidade de visitantes superior a sua capacidade de fornecimento de água. Isso magnifica os problemas de esgotamento sanitário.

A obtenção qualiquantitativa de água para o atendimento das necessidades básicas da humanidade e, por extensão, de seus usos múltiplos, é um dos principais problemas já a partir da virada deste milênio. A missão é mais complexa quando essa abordagem ocorre em regiões semiáridas, com suas intempéries ambientais. Embora a gestão dos recursos hídricos não seja tarefa das mais simples, nesse contexto, uma otimização do uso, obtenção e armazenamento d'água é indispensável.

Como o abastecimento para as necessidades humanas é prioritário, desde já as demandas para tal fim devem ser garantidas em qualquer cenário considerado, conservando e distribuindo equilibradamente aportes destes recursos vitais em quantidades e qualidades mínimas.

\section{BACIAS HIDROGRÁFICAS INTERMITENTES SAZONAIS E POTENCIALIDADES HIDROAMBIENTAIS NO NORDESTE SETENTRIONAL BRASILEIRO}

Resumo: As bacias hidrográficas no Trópico semiárido brasileiro, em grande maioria, drenam terras secas (áridas, semiáridas e subúmidas secas), formando características fisiográficas bem particulares, com dinâmica hidrológica que depende da renovação espaço-temporal das chuvas a partir basicamente do escoamento superficial, em determinados períodos do ano. Este regime sazonal (intra ou extra-anual) influencia os potenciais hidroambientais da região Nordeste do Brasil. Destacar a influência das renovações das chuvas no regime hidrológico de bacias intermitentes sazonais dessa região é o objetivo deste artigo. Para tanto, foram consideradas as bacias hidrográficas como referencial de análise e planejamento para discussões acerca de suas potencialidades e limitações hidroambientais, frente aos problemas do Trópico semiárido. Temas como contexto geoambiental e gestão de bacias hidrográficas, dinâmica hidrológica e condições hidrogeológicas foram tratados no artigo. 
Palavras-chave: bacias hidrográficas, potencialidades hidroambientais, Trópico semiárido, Nordeste brasileiro.

\section{INTERMITTENT SEASONAL WATERSHEDS AND HYDRO- ENVIRONMENTAL POTENTIALS IN NORTHEAST BRAZIL}

Abstract: Basins in the semiarid Brazilian Tropic, most often drain drylands (arid, semiarid and dry sub-humid), shape particular physiographic characteristics, with a hydrological dynamics that depends on the renewal of rainfall in space-time, mainly from the runoff, at certain times of the year. This seasonal basis (within the same year or from one year to the other) influence hydro-environmental potentialities in Northeastern Brazil. Highlighting the influence of renovation rainfall in the hydrological regime of intermittent seasonal watersheds in this region is the goal of this paper. The following factors were considered to be the Watersheds were taken as reference for analysis and planning for discussions about their strengths and hydro-environmental limitations facing problems associated with semi-arid Tropics. Geo-environmental context and watershed management, hydrological dynamics and hydrogeological conditions were treated in the article.

Keywords: watersheds, potential hydro-environmental, Semi-arid tropics, northeastern Brazil.

\section{Bibliografia}

AB'SABER, A. N. (1974) O Domínio morfoclimático semiárido das caatingas brasileiras. In: Geomorfologia, ${ }^{\circ}$ 43. USP: São Paulo, 37p. BATCHELOR, C.H.; WALLACE, J.S. (1995) Hydrological Process, Dryland Degradation and Integrated Catchment Resource Management. Desertification Control Bulletin. A Bulletin of World Events in the Control of Desertification, Restoration of Degraded Lands an Reforestation. Number 27. United Nations Environment Programme (UNEP), pp.27-34.

BELTRAME, A. da V. (1994) Diagnóstico do meio físico de bacias hidrográficas: modelo e aplicação. Florianópolis: Ed. da UFSC, 112p.

BITTENCOURT, J. S.; MORESCHI, J. B. (2000) Recursos minerais. IN: Decifrando a Terra. São Paulo: Oficina de Textos. Cap. 21. p. 445-470. 
CUNHA, S. B. da. (2001) Bacias hidrográficas. IN: CUNHA, S.B. da; GUERRA, A. J. T. (orgs.). Geomorfologia do Brasil. $2^{\mathrm{a}}$ ed. Rio de Janeiro: Bertrand Brasil, p. 229-276.

; GUERRA, A. J. (orgs.) (2003) Canais fluviais e a questão ambiental. In: A questão ambiental: diferentes abordagens. Rio de Janeiro: Bertrand Brasil, p. 219-237.

DRESCH, Jean. (1987) La influencia del hombre sobre la degradacion de los ecossistemas naturales em los paises de Magreb. In: Programa de las Naciones Unidas para el Médio Ambiente (PNUMA): Comision de la URSS de los Asuntos de PNUMA. Colonizacion de los territórios áridos y lucha contra la desertification: enfoque integral. Moscu: Centro de los Proyectos Internacionales - GKNT, p. 70-72 (Capitulo X).

EBISEMIJU, F. S. (1989) The response of headwater stream channels to urbanization in the humid tropics. Hydrological Processes. vol. 3. p. 237253.

SERVIÇO GEOLÓGICO DO BRASIL/COMPANHIA DE PESQUISA DE RECURSOS MINERAIS (CPRM). (1998) Atlas dos recursos hídricos subterrâneos do Ceará. Fortaleza: CPRM.

MERICO, L. F. K. (1996) Introdução à economia ecológica. Blumenau: Ed. da FURB, p. 1-50.

FILHO, J. G. C. G. (org.). (1994) Projeto Áridas: uma estratégia de desenvolvimento sustentável para o Nordeste. GTII. Recursos Hídricos: II. 2 - Sustentabilidade do Desenvolvimento do Semiárido sob o ponto de vista dos Recursos Hídricos. Brasília. Ed do MMA, 102 p.

MINISTÉRIO DO MEIO AMBIENTE (MMA)/SECRETÁRIA DE RECURSOS HÍDRICOS (SRH). (2004) Documento de Introdução. Plano Nacional de Recursos Hídricos. Iniciando um processo de debate nacional. Brasília: Ed.MMA/SRH, 51p:

NASCIMENTO, F.R. do. (2003) Recursos Naturais e Desenvolvimento Sustentável: Subsídios ao gerenciamento geoambiental na Sub-Bacia do Baixo Pacoti - CE. 154 f. Dissertação (Mestrado em Geografia) Universidade Estadual do Ceará, Fortaleza.

UFG. 244p.

(2013) O Fenômeno da Desertificação. Goiânia: Editora da

; CUNHA, S. B. da; ROSA, M. F.; SOUZA, M. J. N. (2005) GeoEnvironmental analysis and identification of degraded areas susceptible to desertification in a semi-arid, tropical ecozone: the Acaraú river basin in 
northeastern Brazil. Sociedade \& Natureza, Uberlândia, v. especial, p. 361368.

OLIVEIRA, A. de; FERREIRA, E. (2001) Caracterização de Sub-bacias hidrográficas. Lavras: Ed. UFLA/FAEPE, p. 26-38.

PUIGDEFÁBREGAS, Juan; MENDIZABAL, Tereza. (1998) Perspectives on desertification: western Mediterranean. In: Journal of Arid Environments (JAE): International Symposium and Workshop "Combating Desertification: connecting science with Community Action". Vol. 39, article $\mathrm{n}^{\circ}$ ae 980401. Academic Press Limited. Tucson, Arizona: USA, p. 209-224.

REBOUÇAS, A. da C. (1997) Água na região Nordeste: desperdício e escassez. In: Revista Estudos Avançados, 11(29), São Paulo: Edusp, p.127152.

. (2002) Água Doce no Mundo e no Brasil. In: REBOUÇAS, A. da C.; BRAGA, B.; TUNDISI, J. G. (org.). Águas doces no Brasil: capital ecológico, uso e conservação. $2^{a}$ edição. São Paulo: Escrituras Editora, p. 01-37.

SOUZA, M. J. N. de. (coord.). (1998) Diagnóstico e Macrozoneamento ambiental do Estado do Ceará. In: Diagnóstico Geoambiental. v. 1. Fortaleza: Ed. FCPS/SEMACE, 227p.

. (2000) Bases naturais e esboço do zoneamento geoambiental do

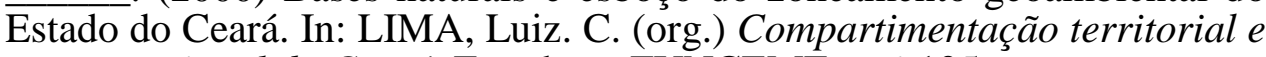
gestão regional do Ceará. Fortaleza: FUNCEME, p 6-105.

; OLIVEIRA, Vládia P.V. (2003) Physical and Environmental Context in the State of Ceará. In: KROL, Thomas G. \& ARAÚJO, H. Frischkorn (editors). Global Change and Regional Impact: water availability and vulnerability of Ecosystems and Society in the Semiarid Northeast of Brazil. Berlin; Heidelberg; New York; Hong Kong; London; Milan; Paris; Tokyo: Springer, p. 95-104.

VIEIRA, V. P.P.B. (2002.) Água Doce no Semiárido. In: REBOUÇAS, A. da C.; BRAGA, B.; TUNDISI, J. G. (org.). Águas Doces no Brasil: capital ecológico, uso e conservação. $2^{a}$ edição. São Paulo: Escrituras Editora, p. 507-530.

Data de submissão: 15/04/2014.

Data de aprovação: 15/11/2014. 